\title{
Hip fractures are preventable: a proposal for osteoporosis screening and fall prevention in older people
}

\author{
Timothy CY Kwok *, SW Law, Edward MF Leung, Dicky TK Choy, Patti MS Lam, Jason CS Leung, \\ SH Wong, TP Ip, CL Cheung
}

\section{A B S T R A C T}

Osteoporosis is highly prevalent but underdiagnosed and undertreated in Hong Kong. Fragility fractures associated with osteoporosis often result in loss of independence and increased mortality for home-dwelling patients, imposing a high socioeconomic burden on society. This issue requires urgent attention given the rapid growth of the elderly population in Hong Kong by approximately $4.3 \%$ each year. To address this situation, a group of experts convened to discuss practical ways to reduce the burden of fractures and formulated three recommendations: first, all men (aged $\geq 70$ years) and women (aged $\geq 65$ years) should receive universal dual-energy X-ray absorptiometry assessment for osteoporosis. Second, all men (aged $\geq 70$ years) and women (aged $\geq 65$ years) with a fracture-risk assessment-derived 10-year risk (hip fracture with bone mineral density) $\geq 3 \%$ should receive $\geq 3$ years of anti-osteoporotic treatment. Third, comprehensive structured assessment (including dual-energy X-ray absorptiometry) should be conducted in older patients with a history of falling. By implementing these recommendations, we estimate that we could prevent 5234 hip fractures in 10 years, an annual incidence reduction of approximately $7 \%$, and save HK\$425 million in direct medical costs plus substantial indirect savings. Ample clinical and costeffectiveness data support these recommendations, and studies in Hong Kong and abroad could serve as models on how to implement them. We are confident that by applying these recommendations rigorously and systematically, a significant reduction in hip fractures in Hong Kong is achievable.

\section{Hong Kong Med J 2020;26:227-35}

https://doi.org/10.12809/hkmj198337

1,2,3 TCY Kwok *, MD, FHKAM (Medicine)

${ }_{3,4}$ SW Law, MB, ChB, FHKAM (Orthopaedic Surgery)

${ }^{3,5}$ EMF Leung, MB, BS, FRCP

${ }^{2,3}$ DTK Choy, MB, ChB, DCH

2 PMS Lam, BSc, MSc (Health Services Management)

2 JCS Leung, MSc

${ }^{6}$ SH Wong, MB, BS, FHKAM (Orthopaedic Surgery)

${ }^{6,7}$ TP Ip, MB, BS, FHKAM (Medicine)

${ }^{6,8}$ CL Cheung, BSc, PhD

Department of Medicine and Therapeutics, Prince of Wales Hospital, The Chinese University of Hong Kong, Hong Kong

Jockey Club Centre for Osteoporosis Care and Control, The Chinese University of Hong Kong, Hong Kong

Hong Kong Osteoporosis Foundation

${ }^{4}$ Department of Orthopaedics and Traumatology, Alice Ho Miu Ling Nethersole Hospital, Hong Kong

5 Hong Kong Association of Gerontology

6 The Osteoporosis Society of Hong Kong

${ }^{7}$ Department of Medicine, Tung Wah Hospital, Hong Kong

Department of Pharmacology and Pharmacy, Li Ka Shing Faculty of

Medicine, The University of Hong Kong, Hong Kong

* Corresponding author: tkwok@cuhk.edu.hk

\section{Introduction}

The Hong Kong eldercare and healthcare system faces a high burden from osteoporosis and hip fragility fractures. The prevalence of osteoporosis in people aged $\geq 50$ years in Hong Kong has been measured as high as $37 \%$ in some studies. ${ }^{1}$ A study of 4000 community-dwelling older people in Hong Kong found that $7 \%$ of men and $11 \%$ of women had $\geq 1$ incident of major osteoporotic fracture over 9.9 and 8.8 years of follow-up, respectively. ${ }^{2}$ The number of patients admitted for hip fracture surgery increased from 3678 in 2000 to an estimated 6300 in $2020,{ }^{3}$ a $71.3 \%$ increase over 20 years. Although the risk of geriatric hip fracture in Hong Kong is declining slightly, this is outweighed by the growing elderly population. ${ }^{3}$ The life expectancy in Hong Kong (81.9 years for men; 87.6 years for women) is among the highest in the world, ${ }^{4,5}$ and projections suggest that by $2036,31.1 \%$ of the population will be aged $\geq 65$ years. ${ }^{6}$ Without intervention, the ageing of the population is predicted to result in a considerable increase in the incidence of fragility fracture, with estimates for hip fractures rising to more than 14500 in $2040 .^{3}$

Direct costs per hip fracture to Hong Kong public hospitals have been estimated at HK\$81 120 (2017 data by $\mathrm{Su}$ et $\mathrm{al}^{7}$ ). This equates to an annual estimated cost of HK\$511 million for the territory's Hospital Authority. Although no estimates of indirect costs are available for Hong Kong, Taiwanese data from 2016 suggest they are likely to be substantial. Estimated annual indirect costs in Taiwan are $\mathrm{HK} \$ 13728, \mathrm{HK} \$ 3744$, or $\mathrm{HK} \$ 9687$ per patient if discharged to a nursing home, foreign-paid home 


\section{䯣骨骨折可預防：老年人骨質疏鬆症篩查和預防 跌倒的建議}

\section{郭志銳、羅尚尉、梁萬福、蔡德基、林文珊、梁志信、}

黃仕雄、葉大鵬、張正龍

骨質疏鬆症在香港非常普遍, 但診斷和治療卻略顯不足。與骨質疏鬆 症相關的脆性骨折除了令社區長者失去自理能力外, 亦會增加死亡 率, 為社會帶來沉重的經濟負擔。鑑於香港的老年人口每年以約 $4.3 \%$ 的速度快速增長, 因此這問題需要得到立即關注。為了解決這種情 況, 專家小組召開會議商討減輕與骨折相關社會經濟負擔的方法, 並 提出三項建議：首先, 所有70歲或以上男性和65歲或以上女性均須接 受DXA骨質密度評估。其次, 所有 10 年內髖骨骨折風險達 $3 \%$ 或以上 (以骨質密度計算的FRAX) 的70歲或以上男性和65歲或以上女性應 接受至少 3 年的骨質疏鬆症藥物治療。第三, 所有曾經跌倒的年長患 者應接受全面有系統的評估（包括DXA評估）。在建議實施後, 我們 估計可在 10 年內預防 5234 例髖骨骨折、每年減少約 $7 \%$ 髖骨骨折率, 並能節省直接醫療費用至少 4.25 億港元及大量間接開支。這些建議得 到大量臨床和成本效益數據支持, 而香港和國外研究可根據這些建議 作為實施的模式。我們堅信通過嚴格和有系統地採用這些建議可大幅 降低香港髖骨骨折病例的數目。 care, or domestic-paid home care, respectively. ${ }^{8} \mathrm{~A}$ Hong Kong study found that $23 \%$ of patients with hip fractures who had previously been living at home were discharged to residential care homes for the elderly. ${ }^{9}$

Follow-up care after hip fracture in Hong Kong is suboptimal, with low usage of bone-enhancing medication with poor follow-up rates. ${ }^{9}$ In a territorywide retrospective study, only $8.2 \%$ of patients were prescribed anti-osteoporotic medication during the year after hip fracture. ${ }^{10}$ Among patients with primary hip fractures, $6 \%$ had fracture complications, and $4 \%$ had secondary fracture(s) within 12 months. ${ }^{9}$ The post-discharge mortality rate was also high: $17.3 \%$ died within 1 year of hip surgery versus $1.6 \%$ of agematched controls. ${ }^{9}$

Local data on other major types of osteoporotic fractures are scarce. In the Hong Kong Osteoporosis Study (HKOS), ${ }^{11}$ the incidence of vertebral fracture was 194 per 100000 person-years in men and 508 per 100000 person-years women aged $\geq 50$ years. ${ }^{12}$ In 2013, in Hong Kong, the prevalence of vertebral fracture was $17 \%$ in men and $30 \%$ in women aged 70 to 79 years. ${ }^{13}$ Many vertebral fractures do not require immediate medical attention, making their impact difficult to study, ${ }^{13}$ but international data suggest they are associated with substantial morbidity, possibly contributing to increased mortality. ${ }^{14}$

European and North American studies have demonstrated that dual-energy X-ray absorptiometry (DXA) screening followed by osteoporosis treatment in older people can substantially reduce hip fracture rates by $25 \%$ to $50 \%$ in $\leq 5$ years and is cost-effective. ${ }^{15-17}$ Therefore, many fractures and associated complications, including secondary fractures and mortality, could be prevented by routine osteoporosis screening in older people and timely treatment initiation in at-risk individuals.

The rising burden of fragility hip fractures demands a response. Based on existing studies from Hong Kong and abroad, we believe that reducing this burden is achievable. Here, we provide clear, practical, evidence-based recommendations on how to reduce hip fracture rates in Hong Kong with the goal of reducing incidence by $6.8 \%$ annually, thereby curbing rising incidence.

\section{Methods}

Roundtable meetings of experts reviewing hip fracture burden in Hong Kong were held in October and December 2018 and June 2019. Tactics to relieve the primary fracture burden were discussed, and a consensus on a rigorous approach to screening, prevention, and treatment was formed.

The calculated predictive performance and simulated effects of our proposed strategies used a similar population to that used by Su et $\mathrm{al}^{18}$ in the $\mathrm{Mr}$ OS and Ms OS Hong Kong Cohort Study, employing the same statistical model and simulation analysis methods. Simulated analysis of the cohort was based on DXA scans of the hip and spine performed on men aged $\geq 70$ years and women aged $\geq 65$ years, without pre-selection, followed by treatment if the Fracture Risk Assessment Tool (FRAX; including bone mineral density [BMD]) score was $\geq 3 \%{ }^{18}$

The number needed to DXA scan and number needed to treat (NNT) were calculated using data derived from the same simulated analysis as that performed by Su et al. ${ }^{18}$ The present epidemiological analysis assumes that only $50 \%$ of eligible patients agree to undergo the DXA scan and engage in followup steps.

\section{Results}

Better awareness of osteoporosis screening and treatment among healthcare providers is urgently needed, as is public financial support for evidencebased tools that can reduce this problem. Discussions resulted in the formulation of three evidence-based recommendations.

\section{Recommendation 1: Universal dual-energy $\mathrm{X}$-ray absorptiometry screening of the hip and spine in all men aged $\geq 70$ years and women aged $\geq 65$ years}

\section{Rationale for using age as screening criterion}

We propose that the lower age limits for screening of women and men be set to 65 and 70 years, respectively, based on a 2017 study showing that the average age of fragility fracture in Hong Kong was 82.1 years. ${ }^{9}$ From ages 65 to 69 years to 70 to 
74 years, the annual incidence of hip fracture rose exponentially from 156.0 to 364.4 per 100000 personyears in women and 102.6 to 212.2 per 100000 person-years in men. ${ }^{19}$ The incidence continued to double in every subsequent 5 -year period. ${ }^{19}$ Our proposed age thresholds align with those specified in international guidelines and reflect the differing ages at which the prevalence of reduced bone mass increases in men and women. ${ }^{15,20}$

\section{Rationale for universal screening}

A prospective cohort study of almost 4000 men and women aged $\geq 65$ years in Hong Kong estimated the effectiveness of hip fracture prevention strategies using DXA. ${ }^{18}$ Based on the calculation method used in this study, we recommend a strategy of universal DXA measurement and treating patients with FRAX (including BMD measurement) risk $\geq 3 \%$. The FRAX threshold of $3 \%$ was selected because our statistical analysis suggests that this prevents the greatest number of hip fractures while maintaining acceptable NNT. Furthermore, this threshold aligns with current local and international treatment guidelines, ${ }^{13}$ and a United States study found that this threshold was cost-effective. ${ }^{21}$

With our strategy, we found that one hip fracture can be prevented for every 111 men (aged $\geq 70$ years) DXA scanned, with 54 subsequently treated; or for every 111 women (aged $\geq 65$ years) DXA scanned, with 73 subsequently treated (Table 1). Using the projected older population of 1.16 million, ${ }^{6}$ and assuming that only $50 \%$ of the target population would be scanned, we could prevent 5234 hip fractures over the next 10 years.

To put the number of hip fractures prevented into context, we considered the projected number of hip fractures and the estimated growth rate. The estimated number of hip fractures in 2020 according to Man et al ${ }^{3}$ was 6300 . If we apply the $4.3 \%$ estimated annual growth of the older population to this figure, ${ }^{6}$ by 2029 , we would expect 9167 hip fractures in Hong Kong. Assuming the same 4.3\% estimated annual increase also applies to the number of fractures prevented each year, ${ }^{6}$ we expect to prevent 431 hip fractures in 2020, and 627 in 2029. Based on these calculations, we estimate that by DXA screening and treating 581000 men and women, the incidence of hip fracture could be reduced by approximately $6.8 \%$ (Table 1). As the estimated growth of the older population is $4.3 \%$ each year, ${ }^{6}$ an $6.8 \%$ annual hip fracture reduction rate would outweigh the annual increase in hip fracture cases among elderly patients due to population growth.

\section{Rationale for using dual-energy X-ray absorptiometry}

We selected DXA for screening because reduced hip BMD in the femoral neck measured by DXA is widely used in treatment guidelines to define osteoporosis and set drug-treatment thresholds. ${ }^{22}$ Hip BMD is strongly associated with hip fracture risk in both men and women ${ }^{23}$ : its association with fragility fracture is stronger than that of spine BMD in Hong Kong Chinese people. ${ }^{24,25}$ Dual-energy X-ray absorptiometry is cheaper than magnetic resonance imaging (each DXA session cost approximately HK\$500 in Hong Kong in 2018); it is noninvasive, and uses less irradiation than computed tomography. ${ }^{26}$ Local guidelines do not recommend the use of quantitative ultrasound for monitoring or treatment of osteoporosis, and currently consider the evidence for peripheral DXA to be insufficient. ${ }^{13}$

This recommendation is supported by health economics studies. Screening strategies based on DXA are more cost-effective in individuals aged $\geq 65$ years than in younger people because hip fracture is rare in the latter..$^{15}$ American and European studies have shown that screening strategies, including DXA screening, are cost-effective for prevention of hip fracture in elderly men and women. ${ }^{15,27}$ A recent Hong Kong study that modelled screening strategies found that DXA-based approaches, including universal DXA with or without pre-screening, were more cost-effective than no screening. ${ }^{7}$ In women aged $\geq 65$ years and men aged $\geq 70$ years, the incremental effectiveness gained by universal DXA screening versus no screening incurred no additional cost, which is well below the widely acceptable willingness to pay (US $\$ 50000$ per qualityadjusted life year). ${ }^{7}$ A modelling analysis using North American data found that universal densitometry and treatment with alendronate was highly cost-

TABLE I. Number of fractures prevented in 10 years through universal DXA scanning in men (aged $\geq 70$ years) and women (aged $\geq 65$ years)

\begin{tabular}{|c|c|c|c|c|c|c|c|}
\hline & Age (years) & $\begin{array}{l}\text { Population (2020 } \\
\text { projection) })^{6}\end{array}$ & $\begin{array}{c}\text { Assumed proportion } \\
\text { of population receiving } \\
\text { DXA (\%) }\end{array}$ & No. of DXA & NN-DXA* & NNT* $^{*}$ & $\begin{array}{l}\text { No. of fractures } \\
\text { saved in } 10 \text { years }\end{array}$ \\
\hline Men & $\geq 70$ & 423000 & 50 & 211500 & 111 & 54 & 1905 \\
\hline Women & $\geq 65$ & 739000 & 50 & 369500 & 111 & 73 & 3329 \\
\hline Total & & 1162000 & & 581000 & & & 5234 \\
\hline
\end{tabular}

Abbreviations: DXA = dual-energy $X$-ray absorptiometry; NN-DXA = number needed to scan; NNT = number needed to treat

* Based on calculation method used in Su et al ${ }^{18}$ 
effective for women aged $\geq 65$ years, and it was costsaving for ambulatory women aged $\geq 85$ years. ${ }^{28}$ The International Society for Clinical Densitometry recommends DXA assessment for all women and men aged $\geq 65$ and $\geq 70$ years, respectively. ${ }^{29}$ While the United States Preventative Services Task Force recommends screening in women aged $\geq 65$ years and in younger postmenopausal women with elevated risk, it makes no recommendation for men because of insufficient evidence. ${ }^{22}$ In Hong Kong, however, the analysis of Su et $\mathrm{al}^{18}$ which is based on extensive local data, suggested that strategies using DXA, including universal screening, can potentially be cost-effective for fracture prevention in both men and women at the age thresholds we propose. Other countries such as Australia, Malaysia, Japan, and Singapore also wholly or partially fund universal DXA screening for older people. ${ }^{30-33}$

Recommendation 2: $\geq 3$ years of treatment with antiresorptive therapy for all men aged $\geq 70$ years and women aged $\geq 65$ years with Fracture Risk Assessment Tool score $\geq 3 \%$

Rationale for using Fracture Risk Assessment Tool to guide treatment

Scanning alone would only be impactful if followed up by a treatment plan. We recommend using FRAX to guide treatment because it calculates the 10-year fracture risk from a patient's age, body mass index, and risk-factor profile (fracture history, family history, tobacco or alcohol use, use of oral glucocorticoids, and presence of rheumatoid arthritis). ${ }^{34}$ It can be used with or without BMD data; it is the most widely adopted fracture risk assessment tool, and FRAX has been extensively validated and adapted to local populations, including that of Hong Kong. ${ }^{34,35}$

The FRAX risk thresholds are widely used to guide intervention in local and international osteoporosis treatment guidelines. ${ }^{13,36}$ The 2019 European guidelines recommend country-specific use of FRAX to assess risk in postmenopausal women, including BMD in intermediate-risk individuals. ${ }^{34} \mathrm{An}$ example of a successful real-world fragility fracturereducing intervention incorporating FRAX has been documented. ${ }^{37}$ A United Kingdom trial used a questionnaire incorporating FRAX to promote DXA screening in women aged 70 to 85 years, leading to a $28 \%$ hip fracture reduction over 5 years. ${ }^{37}$

\section{Rationale for treatment duration of $\geq 3$ years}

We suggest 3 years as the duration of antiresorptive treatment based on local studies of alendronate, which showed increases in BMD of $5 \%$ to $6 \%$ at the lumbar spine and $3 \%$ to $4 \%$ at the hip after 1 year of treatment in postmenopausal women with osteoporosis. ${ }^{38,39}$ Local guidelines recommend 5 years of initial therapy with oral bisphosphonates but acknowledge that no consensus exists regarding the optimal treatment duration. ${ }^{13}$ We believe that 3 years of duration offers an appropriate balance of efficacy and cost. Additional financial support for longer-term therapy may become feasible when our recommendations begin demonstrating effectiveness in fragility fracture reduction, with improved compliance, during the first 3 years.

\section{Rationale for treatment with antiresorptive drugs}

Current osteoporosis treatments are appropriate for addressing the hip fracture burden in Hong Kong (Table $2^{13}$ ). The efficacy and safety of locally approved

TABLE 2. Approved antiresorptive therapies for osteoporosis in Hong Kong, adapted from Osteoporosis Society of Hong Kong 2013 Guidelines $^{13}$

\begin{tabular}{|c|c|c|c|c|c|}
\hline \multirow[t]{2}{*}{ Antiresorptive agent } & \multicolumn{2}{|c|}{ Approved indications* } & \multicolumn{3}{|c|}{ Documented fracture reduction } \\
\hline & Prevention & Treatment & Vertebral & Non-vertebral & Hip \\
\hline Hormone replacement therapy & + & - & + & + & + \\
\hline Raloxifene & + & + & + & $\mathrm{NA}^{\dagger}$ & $\mathrm{NA}^{\dagger}$ \\
\hline Calcitonin & - & + & + & $\mathrm{NA}^{\dagger}$ & $\mathrm{NA}^{\dagger}$ \\
\hline Alendronate & + & + & + & + & + \\
\hline Risedronate & + & + & + & + & + \\
\hline Ibandronate & + & + & + & $+^{\ddagger}$ & $\mathrm{NA}^{\dagger}$ \\
\hline Zoledronic acid & + & + & + & + & + \\
\hline Denosumab & + & + & + & + & + \\
\hline \multicolumn{6}{|c|}{ - All patients on antiresorptive therapy should receive calcium and vitamin D supplementation } \\
\hline \multicolumn{6}{|c|}{ - All patients should receive lifestyle education on how to minimise the risk of fragility fractures } \\
\hline \multicolumn{6}{|c|}{$\begin{array}{l}\text { * Approved by United States Food and Drug Administration or European Medicines Agency } \\
+ \text { Lack of demonstrable effect at these sites should be considered in the context that studies may not have been adequately powered } \\
\neq \text { Post-hoc analysis }\end{array}$} \\
\hline
\end{tabular}


antiresorptive therapies have been extensively validated in numerous clinical trials in men and postmenopausal women, including long-term studies. ${ }^{40-42}$ Cost-effectiveness analyses support their use for fracture prevention, with gains in qualityadjusted life years for patients and incremental cost-effectiveness ratios well within acceptability thresholds (vs no treatment). ${ }^{7,21}$ A meta-analysis of eight studies of four agents found that antiresorptive therapy for osteoporosis led to significant mortalityrate reductions. ${ }^{43}$ Recently, a study in Hong Kong showed that real-world use of bisphosphonates among hip fracture patients may protect against cardiovascular diseases. ${ }^{10}$ Adverse event (AE) imbalances suggesting cardioprotective effects were also observed in a randomised trial of zoledronate in 2000 women with osteopenia in New Zealand. ${ }^{44}$ Bisphosphonates are easily accessible in Hong Kong, and many patients with osteoporosis could feasibly be treated in primary care. ${ }^{13}$ Our analysis found that, with universal DXA scanning of men aged $\geq 70$ years and women aged $\geq 65$ years, a treatment threshold of FRAX (with BMD) risk $\geq 3 \%$ for hip fracture yields a NNT of 54 for men and 73 for women to prevent one fracture.

In line with local treatment guidelines, we recommend lifestyle measures, including a balanced diet rich in calcium and vitamin $\mathrm{D}$, regular exercise, avoidance of smoking or excessive alcohol intake, and adequate sunlight exposure, as a universal approach to prevention and non-pharmacological management of osteoporosis. ${ }^{13}$ Vitamin D supplementation should be given alongside antiresorptive medications, and calcium supplementation is recommended for those unable to achieve adequate levels through diet alone. ${ }^{13}$ This is particularly pertinent in Hong Kong, where dietary vitamin $\mathrm{D}$ intake is generally low and the prevalence of vitamin D insufficiency or deficiency has been observed to be high. ${ }^{45} \mathrm{~A}$ Cochrane systematic review found that exercise has a small but significant effect on BMD in postmenopausal women with osteoporosis. ${ }^{46}$ People with osteoporosis and high hip fracture risk should be treated with antiresorptive drugs combined with calcium or vitamin D and physical exercise.

Osteonecrosis of the jaw (ONJ) and atypical femoral fracture (AFF) are well-known AEs of antiresorptive therapies. ${ }^{13,47}$ However, the absolute risk of ONJ with the administration of antiresorptive therapy in patients with osteoporosis patients is low, and the risk-benefit balance is highly favourable. ${ }^{48,49}$ Risk-minimising precautions against ONJ, including close attention to good dental hygiene during treatment and endodontic (rather than surgical) corrective procedures, have already been incorporated into local guidelines. ${ }^{13}$

Poor adherence is a challenge for long-term use of oral bisphosphonates in osteoporosis. ${ }^{50,51}$ One study showed persistence declining to $<50 \%$ over 2 years. ${ }^{51}$ Factors associated with poor adherence include advanced age, fear of AEs, and inadequate education. ${ }^{52}$ Improving patient education, ${ }^{53}$ using antiresorptive therapies with longer dosing intervals, ${ }^{54}$ and managing AEs appropriately may help to improve adherence. ${ }^{55}$

\section{Cost of Recommendations 1 and 2}

For screening and follow-up treatment programmes to be worthwhile, assessing the cost-benefit ratio is important. The estimated costs of Recommendation 1 (universal DXA screening in men aged $\geq 70$ years and women aged $\geq 65$ years) in 10 years are shown in Table $3 .{ }^{25}$

We assumed that 3 years of generic alendronate plus calcium and vitamin D supplementation would be given for treatment, costing approximately HK\$2500 (accounting for inflation; Table $3^{25}$ ). We chose alendronate because it is currently the lowest-priced generic antiresorptive; patients may self-fund other options should they prefer. For instance, denosumab may be an option, particularly for patients with high fracture risk, poor adherence, contraindications, or intolerance to bisphosphonates. ${ }^{13,49}$ The incidence of ONJ in bisphosphonate-treated patients with osteoporosis in Hong Kong appears to be low (73.53 per 100000 person-years of oral treatment), and

TABLE 3. Estimated costs of DXA, drug treatment, and hip fractures prevented in 10 years

\begin{tabular}{|c|c|c|c|c|c|c|c|}
\hline & $\begin{array}{c}\text { Age } \\
\text { (years) }\end{array}$ & No. of DXA* & $\begin{array}{c}\text { No. of fractures saved in } \\
10 \text { years* }\end{array}$ & $\begin{array}{c}\text { No. of patients } \\
\text { prescribed drug }\end{array}$ & $\begin{array}{c}\text { Cost of } \\
\text { DXA }^{25} \text { (HK\$) }\end{array}$ & $\begin{array}{l}\text { Cost of drug for } \\
3 \text { years }{ }^{\ddagger} \text { (HK\$) }\end{array}$ & Total cost (HK\$) \\
\hline Men & $\geq 70$ & 211500 & 1905 & 102870 & & 2500 & 257 million \\
\hline Women & $\geq 65$ & 369500 & 3329 & 243017 & & 2500 & 608 million \\
\hline \multirow[t]{2}{*}{ Total } & & 581000 & 5234 & & 500 & & 291 million \\
\hline & & & & & & & 1155 million \\
\hline
\end{tabular}

Abbreviations: DXA = dual-energy X-ray absorptiometry; NNT = number needed to treat

* Based on Table I

+ No. of fractures saved in 10 years $\times$ NNT*

‡ Authors' assumption of cost data: alendronate, $\mathrm{HK} \$ 50$ per month; calcium/vitamin D supplement, HK\$I 5 per month; inflation $3 \%$ per year 
the reported cases were in patients with readily modifiable risk factors. ${ }^{56}$ Estimates for the incidence of AFF in Hong Kong are not available, but data from abroad suggest that AFF is also very rare (13.6 per 100000 patient-years at 2.0-3.9 years of bisphosphonate use). ${ }^{57}$ On this basis, we have not included the costs associated with ONJ and AFF in our calculations, as the associated cost is likely to be low.

The total cost of Recommendations 1 and 2 is HK $\$ 1155$ million in 10 years (Table $3^{25}$ ). In terms of benefits, we estimate that our proposals will prevent 5234 hip fractures over 10 years; if the estimated direct cost per hip fracture is HK\$81 120 (2017), ${ }^{7}$ this would save the healthcare system HK\$425 million in 10 years, with further savings from reduced outpatient and indirect costs. Additionally, elderly people and their families would avoid costs associated with institutional care. Based on 6300 hip fractures in Hong Kong in $2020,{ }^{3}$ fracture reduction of $6.8 \%$, the proportion of all patients with hip fractures discharged to institutional care (17\%), ${ }^{9}$ and local institutional care costs ( $\mathrm{HK} \$ 120000$ annually for 5 years), we estimate that the savings from reduced institutional care needs would be HK\$534 million in 10 years. Therefore, the total cost savings would be HK\$959 million over 10 years; it should be noted, though, that this estimation is conservative and has not taken into account the year-on-year increase in hip fracture rate or inflation. Although the prevention of hip fractures alone may not reduce the institutional care cost for all patients, it would still likely be associated with substantial cost savings for the majority of patients. A full cost-effectiveness analysis of our proposal has not been performed, but the above cost-savings calculation has not included other fragility fractures, indirect healthcare cost savings (eg, transportation, costs associated with work productivity in family members), and inflation. Therefore, we believe that our recommendations are potentially cost-effective.

\section{Recommendation 3: Comprehensive structured assessment (including dual-energy $\mathrm{X}$-ray absorptiometry) of older people with a history of falling}

\section{Rationale for assessing patients with a history of falls}

Because of ageing of muscles and declining balance control, older adults are more likely to experience falls than their younger counterparts. ${ }^{58}$ Fall history is a risk factor for subsequent falls ${ }^{59-61}$ and an independent predictor of fracture in older men and women. ${ }^{62}$ Recently, a hip fracture prediction score (HKOS score) was developed and validated for older adults aged $\geq 80$ years in Hong Kong, and fall history is one of the risk factors included. ${ }^{63}$
Older people who have a history of falling should therefore be offered a comprehensive fall risk assessment. We also recommend DXA screening in these high-risk individuals. Although a history of falling is a good reason for fall risk and DXA assessments, these assessments should not be confined to those with a history of falling. Guidelines from the American Geriatrics Society/British Geriatrics Society recommend annual screening of all community-dwelling older people aged $\geq 65$ years for falls and risk of falling. ${ }^{64}$

A meta-analysis of 159 trials in over 79000 community-dwelling patients, including diverse fall-risk reduction strategies, concluded that home or group-based exercise programmes, including Tai Chi and home modifications, can reduce fall risk and fall-related fracture. ${ }^{65}$ In a study of elderly Hong Kong patients with a history of falling, a single risk assessment and home modification visit by an occupational therapist resulted in a reduced fall prevalence in the following 12 months compared with controls ( $13.7 \%$ vs $20.4 \%, \mathrm{P}=0.03) .{ }^{66}$

\section{Suggestions for provision of care}

Table $4^{13}$ summarises the key elements of our recommendations, including treatment thresholds specified by local guidelines. Osteoporosis and fall risk assessment can be managed in the primary care setting, especially in Hong Kong, where access to DXA screening is excellent.

To promote DXA screening, Shepstone et $\mathrm{al}^{37}$ showed that a self-completed questionnaire capturing FRAX risk factors was effective at alerting older women to their fracture risk, resulting in a $28 \%$ reduction in hip fracture incidence in 5 years. On the basis of local prospective data, we demonstrated that combining a short questionnaire for sarcopenia (SARC-F) and the FRAX questionnaire could identify $>75 \%$ of older people who suffered an incident hip fracture within 10 years. ${ }^{18}$ Furthermore, the wellcalibrated HKOS score may accurately identify the oldest old ( $\geq 80$ years) who are at high hip fracture risk. ${ }^{63}$

\section{Conclusion and call to action}

The high primary hip fracture burden in Hong Kong can be reduced with an evidence-based screening programme. High-risk patients identified by our proposed screening can be effectively managed using well-established and affordable therapies within the primary care field. Our proposals are supported by extensive evidence: similar programmes have shown efficacy, both in Hong Kong and abroad.

We propose that the Hong Kong government provide public funding support for a universal DXA screening programme for all men aged $\geq 70$ years and women aged $\geq 65$ years. Patients with a 
TABLE 4. Summary of recommendations for different population subgroups and treatment thresholds ${ }^{13}$

\begin{tabular}{|c|c|c|}
\hline & $\begin{array}{l}\text { All men aged } \geq 70 \text { years and } \\
\text { women aged } \geq 65 \text { years }\end{array}$ & Men and women with a history of falls \\
\hline Assessment & Receive DXA scan & $\begin{array}{l}\text { - Receive structured fall risk-assessment and fall risk- } \\
\text { reduction intervention; and } \\
\text { - Receive DXA scan }\end{array}$ \\
\hline Management & \multicolumn{2}{|c|}{$\begin{array}{l}\text { Pharmacological treatment for } \geq 3 \text { years if these thresholds are met: } \\
\text { - BMD T-score } \leq-2.5 \text { at lumbar spine or proximal femur; or } \\
\text { - BMD T-score }-1 \text { to }-2.5 \text { and FRAX } 10 \text {-year risk (with BMD) for hip fracture } \geq 3 \% \\
\text { Below treatment thresholds: } \\
\text { - Receive lifestyle advice on how to reduce fracture risks; and } \\
\text { - Re-evaluate if appropriate }\end{array}$} \\
\hline
\end{tabular}

Abbreviations: BMD = bone mineral density; DXA = dual-energy X-ray absorptiometry; FRAX = Fracture Risk Assessment Tool

history of falling must receive systematic fracturerisk evaluations; patients with high fracture risk identified through these measures should be treated with antiresorptive agents and receive appropriate multidisciplinary follow-up.

We recommend a multidisciplinary effort including colleagues in general practice, orthopaedics, geriatric medicine, etc, to improve awareness of already available screening tools and effective treatment options for osteoporosis. If properly implemented and supported, we believe that our goal of a $7 \%$ annual reduction in hip fracture incidence in Hong Kong can be achieved, helping to offset the annual increase in the elderly population. Adoption of our proposals will shift government spending from post-fracture management to proactive osteoporosis management and fracture prevention. If our proposals are adopted, the estimated HK\$1 billion that would be spent in 10 years on post-fracture management will instead be spent on improved osteoporosis management and fracture prevention for tens of thousands of patients. Furthermore, preventing fractures would also preserve the quality of life of many patients and their families. Achieving better control of hip fracture burden will be challenging, but it is well within our reach.

\section{Author contributions}

All authors contributed to the literature review and recommendations, critically revised the manuscript for important intellectual content, approved the final version for publication, and take responsibility for its accuracy and integrity.

\section{Conflicts of interest}

This publication is funded by a supportive grant from Amgen Asia Holding Limited to the Hong Kong Osteoporosis Foundation (HKOF) and the Osteoporosis Society of Hong Kong (OSHK) Consensus Group on Prevention of Fractures in Older People. All authors declare that they have no additional conflicts of interest.

\section{Acknowledgement}

Editorial support for this manuscript was provided by Magdalene Chu and Dr Alister Smith of MIMS Hong Kong, funded by the Hong Kong Osteoporosis Foundation.

\section{Funding/support}

This publication is funded by a supportive grant from Amgen Asia Holding Limited to the Hong Kong Osteoporosis Foundation (HKOF) and the Osteoporosis Society of Hong Kong (OSHK) Consensus Group on Prevention of Fractures in Older People.

\section{References}

1. Yu F, Xia W. The epidemiology of osteoporosis, associated fragility fractures, and management gap in China. Arch Osteoporos 2019;14:32.

2. Su Y, Leung J, Hans D, Aubry-Rozier B, Kwok T. Added clinical use of trabecular bone score to BMD for major osteoporotic fracture prediction in older Chinese people: the Mr. OS and Ms. OS cohort study in Hong Kong. Osteoporos Int 2017;28:151-60.

3. Man LP, Ho AW, Wong SH. Excess mortality for operated geriatric hip fracture in Hong Kong. Hong Kong Med J 2016;22:6-10.

4. The World Bank. World Development Indicators. Available from: https://datacatalog.worldbank.org/dataset/worlddevelopment-indicators. Accessed 18 Mar 2019.

5. Department of Health, Hong Kong SAR Government. Life expectancy. Available from: https://www.healthyhk.gov. hk/phisweb/en/healthy_facts/health_indicators/life_exp/. Accessed 3 Dec 2019.

6. Census and Statistics Department, Hong Kong SAR Government. Hong Kong Population Projections 20172066. Available from: https://www.statistics.gov.hk/pub/ B1120015072017XXXXB0100.pdf. Accessed 1 Dec 2019.

7. Su Y, Lai FT, Yip BH, Leung JC, Kwok TC. Costeffectiveness of osteoporosis screening strategies for hip fracture prevention in older Chinese people: a decision tree modeling study in the Mr. OS and Ms. OS cohort in Hong Kong. Osteoporos Int 2018;29:1793-805.

8. Chan DC, McCloskey EV, Chang CB, et al. Establishing and evaluating FRAX ${ }^{\circ}$ probability thresholds in Taiwan. J Formos Med Assoc 2017;116:161-8.

9. Leung KS, Yuen WF, Ngai WK, et al. How well are we 
managing fragility hip fractures? A narrative report on the review with the attempt to setup a Fragility Fracture Registry in Hong Kong. Hong Kong Med J 2017;23:264-71.

10. Sing CW, Wong AY, Kiel DP, et al. Association of alendronate and risk of cardiovascular events in patients with hip fracture. J Bone Miner Res 2018;33:1422-34.

11. Cheung CL, Tan KC, Kung AW. Cohort Profile: The Hong Kong Osteoporosis Study and the follow-up study. Int J Epidemiol 2018;47:397-8f.

12. Bow $\mathrm{CH}$, Cheung E, Cheung $\mathrm{CL}$, et al. Ethnic difference of clinical vertebral fracture risk. Osteoporos Int 2012;23:87985.

13. OSHK Task Group for Formulation of 2013 OSHK Guideline for Clinical Management of Postmenopausal Osteoporosis in Hong Kong, Ip TP, Cheung SK, et al. The Osteoporosis Society of Hong Kong (OSHK): 2013 OSHK guideline for clinical management of postmenopausal osteoporosis in Hong Kong. Hong Kong Med J 2013;19 Suppl 2:1-40.

14. Hirsch JA, Beall DP, Chambers MR, et al. Management of vertebral fragility fractures: a clinical care pathway developed by a multispecialty panel using the RAND/ UCLA Appropriateness Method. Spine J 2018;18:2152-61.

15. Dell R, Greene D. Is osteoporosis disease management cost effective? Curr Osteoporos Rep 2010;8:49-55.

16. Dell R, Greene D, Schelkun SR, Williams K. Osteoporosis disease management: the role of the orthopaedic surgeon. J Bone Joint Surg Am 2008;90 Suppl 4:188-94.

17. Newman ED, Ayoub WT, Starkey RH, Diehl JM, Wood GC. Osteoporosis disease management in a rural health care population: hip fracture reduction and reduced costs in postmenopausal women after 5 years. Osteoporos Int 2003;14:146-51

18. Su Y, Woo JW, Kwok TC. The added value of SARC-F to prescreening using FRAX for hip fracture prevention in older community adults. J Am Med Dir Assoc 2019;20:839.

19. Tsang SW, Kung AW, Kanis JA, Johansson H, Oden A. Ten-year fracture probability in Hong Kong Southern Chinese according to age and BMD femoral neck T-scores. Osteoporos Int 2009;20:1939-45.

20. Cheung CL, Ang SB, Chadha M, et al. An updated hip fracture projection in Asia: the Asian Federation of Osteoporosis Societies study. Osteoporos Sarcopenia 2018;4:16-21.

21. Tosteson AN, Melton LJ 3rd, Dawson-Hughes B, et al Cost-effective osteoporosis treatment thresholds: the United States perspective. Osteoporos Int 2008;19:437-47.

22. US Preventive Services Task Force, Curry SJ, Krist AH, et al. Screening for Osteoporosis to prevent fractures: US preventive services task force recommendation statement. JAMA 2018;319:2521-31.

23. Cummings SR, Cawthon PM, Ensrud KE, et al. BMD and risk of hip and nonvertebral fractures in older men a prospective study and comparison with older women. J Bone Miner Res 2006;21:1550-6.

24. Kung AW, Lee KK, Ho AY, Tang G, Luk KD. Ten-year risk of osteoporotic fractures in postmenopausal Chinese women according to clinical risk factors and BMD T-scores: a prospective study. J Bone Miner Res 2007;22:1080-7.

25. Bow CH, Tsang SW, Loong CH, Soong CS, Yeung SC, Kung AW. Bone mineral density enhances use of clinical risk factors in predicting ten-year risk of osteoporotic fractures in Chinese men: the Hong Kong Osteoporosis Study. Osteoporos Int 2011;22:2799-807.

26. Choi YJ. Dual-energy X-ray absorptiometry: beyond bone mineral density determination. Endocrinol Metab (Seoul) 2016;31:25-30.

27. Nayak S, Greenspan SL. Cost-effectiveness of osteoporosis screening strategies for men. J Bone Miner Res 2016;31:1189-99.

28. Schousboe JT, Ensrud KE, Nyman JA, Melton LJ 3rd, Kane RL. Universal bone densitometry screening combined with alendronate therapy for those diagnosed with osteoporosis is highly cost-effective for elderly women. J Am Geriatr Soc 2005;53:1697-704.

29. International Society for Clinical Densitometry. 2019 ISCD Official Positions-Adult. International Society for Clinical Densitometry (ISCD). Available from: https://www.iscd. org/official-positions/2019-iscd-official-positions-adult/. Accessed 7 Aug 2019.

30. The Department of Health. Australian Government. Bone densiometry. Available from: https://www1.health.gov.au/ internet/main/publishing.nsf/Content/diagnosticimagingbd.htm. Accessed 7 Aug 2019.

31. International Osteoporosis Foundation. 2013 AsiaPacific Audit: Malaysia. Available from: https:// www.iofbonehealth.org/sites/default/files/media/ PDFs/Regional\%20Audits/2013-Asia_Pacific_AuditMalaysia_0_0.pdf. Accessed 23 Oct 2019.

32. International Osteoporosis Foundation. The Asian Audit. Epidemiology, costs and burden of osteoporosis in Asia 2009. Available from: https://www.iofbonehealth.org/ sites/default/files/PDFs/Audit\%20Asia/Asian_regional_ audit_2009.pdf. Accessed 23 Oct 2019.

33. International Osteoporosis Foundation. 2013 AsiaPacific Audit: Singapore. Available from: https:// www.iofbonehealth.org/sites/default/files/media/ PDFs/Regional\%20Audits/2013-Asia_Pacific_AuditSingapore_0_0.pdf. Accessed 23 Oct 2019.

34. Kanis JA, Cooper C, Rizzoli R, et al. European guidance for the diagnosis and management of osteoporosis in postmenopausal women. Osteoporos Int 2019;30:3-44.

35. The University of Sheffield, UK. FRAX Fracture Risk Assessment Tool (Hong Kong). Available from: https:// www.sheffield.ac.uk/FRAX/tool.aspx? country $=20$. Accessed 20 Mar 2019.

36. Kanis JA, Harvey NC, Cooper C, et al. A systematic review of intervention thresholds based on FRAX: a report prepared for the National Osteoporosis Guideline Group and the International Osteoporosis Foundation. Arch Osteoporos 2016;11:25.

37. Shepstone L, Lenaghan E, Cooper C, et al. Screening in the community to reduce fractures in older women (SCOOP): a randomised controlled trial. Lancet 2018;391:741-7.

38. Kung AW, Yeung SS, Chu LW. The efficacy and tolerability of alendronate in postmenopausal osteoporotic Chinese women: a randomized placebo-controlled study. Calcif Tissue Int 2000;67:286-90.

39. Lau EM, Woo J, Chan YH, Griffith J. Alendronate prevents bone loss in Chinese women with osteoporosis. Bone 2000;27:677-80

40. Tu KN, Lie JD, Wan CK, et al. Osteoporosis: a review of treatment options. P T 2018;43:92-104.

41. Zhou J, Ma X, Wang T, Zhai S. Comparative efficacy of bisphosphonates in short-term fracture prevention for 
primary osteoporosis: a systematic review with network meta-analyses. Osteoporos Int 2016;27:3289-300.

42. Lyu H, Jundi B, Xu C, et al. Comparison of denosumab and bisphosphonates in osteoporosis patients: a meta-analysis of randomized controlled trials. J Clin Endocrinol Metab 2019;104:1753-65.

43. Bolland MJ, Grey AB, Gamble GD, Reid IR. Effect of osteoporosis treatment on mortality: a meta-analysis. J Clin Endocrinol Metab 2010;95:1174-81.

44. Reid IR, Horne AM, Mihov B, et al. Fracture prevention with zoledronate in older women with osteopenia. N Engl J Med 2018;379:2407-16.

45. Leung RY, Cheung BM, Nguyen US, Kung AW, Tan KC, Cheung CL. Optimal vitamin D status and its relationship with bone and mineral metabolism in Hong Kong Chinese. Bone 2017;97:293-8.

46. Howe TE, Shea B, Dawson LJ, et al. Exercise for preventing and treating osteoporosis in postmenopausal women. Cochrane Database Syst Rev 2011;(7):CD000333.

47. Amgen. Prolia (denosumab prescribing information). Highlights of prescribing information. Prolia (denosumab prescribing information). Available from: https://www. pi.amgen.com/ /media/amgen/repositorysites/pi-amgencom/prolia/prolia_pi.pdf. Accessed 25 Apr 2019.

48. Khan AA, Morrison A, Hanley DA, et al. Diagnosis and management of osteonecrosis of the jaw: a systematic review and international consensus. J Bone Miner Res 2015;30:3-23.

49. Bone HG, Wagman RB, Brandi ML, et al. 10 Years of denosumab treatment in postmenopausal women with osteoporosis: results from the phase 3 randomised FREEDOM trial and open-label extension. Lancet Diabetes Endocrinol 2017;5:513-23.

50. Abrahamsen B. Are long-term bisphosphonate users a reality? Dose years for current bisphosphonate users assessed using the Danish National Prescription Database. Osteoporos Int 2013;24:369-72.

51. Burden AM, Paterson JM, Solomon DH, Mamdani M, Juurlink DN, Cadarette SM. Bisphosphonate prescribing, persistence and cumulative exposure in Ontario, Canada. Osteoporos Int 2012;23:1075-82.

52. Diab DL, Watts NB. Postmenopausal osteoporosis. Curr Opin Endocrinol Diabetes Obes 2013;20:501-9.

53. Sewerynek E, Horst-Sikorska H, Stępień-Kłos W, et al. The role of counselling and other factors in compliance of postmenopausal osteoporotic patients to alendronate 70 therapy. Arch Med Sci 2013;9:288-96.

54. Cooper A, Drake J, Brankin E, PERSIST Investigators. Treatment persistence with once-monthly ibandronate and patient support vs. once-weekly alendronate: results from the PERSIST study. Int J Clin Pract 2006;60:896-905.

55. Inderjeeth CA, Inderjeeth AJ, Raymond WD. Medication selection and patient compliance in the clinical management of osteoporosis. Aust Fam Physician 2016;45:814-7.

56. Kwok T, Choy TK, Kwok WL. Prevalence of bisphosphonate-related osteonecrosis of the jaw in Hong Kong. Hong Kong Med J 2016;22 Suppl 2:S46-7.

57. Dell RM, Adams AL, Greene DF, et al. Incidence of atypical nontraumatic diaphyseal fractures of the femur. J Bone Miner Res 2012;27:2544-50.

58. Guerado E, Sandalio RM, Caracuel Z, Caso E. Understanding the pathogenesis of hip fracture in the elderly, osteoporotic theory is not reflected in the outcome of prevention programmes. World J Orthop 2016;7:218-28.

59. Scott V, Votova K, Scanlan A, Close J. Multifactorial and functional mobility assessment tools for fall risk among older adults in community, home-support, long-term and acute care settings. Age Ageing 2007;36:130-9.

60. Wu TY, Chie WC, Yang RS, Kuo KL, Wong WK, Liaw CK. Risk factors for single and recurrent falls: a prospective study of falls in community dwelling seniors without cognitive impairment. Prev Med 2013;57:511-7.

61. Woo J, Leung J, Wong S, Kwok T, Lee J, Lynn $H$. Development of a simple scoring tool in the primary care setting for prediction of recurrent falls in men and women aged 65 years and over living in the community. J Clin Nurs 2009;18:1038-48.

62. Harvey NC, Odén A, Orwoll E, et al. Falls predict fractures independently of FRAX probability: a meta-analysis of the osteoporotic fractures in men (MrOS) study. J Bone Miner Res 2018;33:510-6.

63. Lam MT, Sing CW, Li GH, Kung AW, Tan KC, Cheung CL. Development and validation of a risk score to predict the first hip fracture in the oldest old: a retrospective cohort study. J Gerontol A Biol Sci Med Sci 2020;75:980-6.

64. Panel on Prevention of Falls in Older Persons, American Geriatrics Society, British Geriatrics Society. Summary of the Updated American Geriatrics Society/British Geriatrics Society clinical practice guideline for prevention of falls in older persons. J Am Geriatr Soc 2011;59:148-57.

65. Gillespie LD, Robertson MC, Gillespie WJ, et al. Interventions for preventing falls in older people living in the community. Cochrane Database Syst Rev 2012;(9):CD007146.

66. Chu MM, Fong KN, Lit AC, et al. An occupational therapy fall reduction home visit program for community-dwelling older adults in Hong Kong after an emergency department visit for a fall. J Am Geriatr Soc 2017;65:364-72. 